\title{
The Scope of Clinical Thoracic Surgery Practice in Nigeria: 13-Year Single Center Review
}

\author{
Ikechukwu Nwafor ${ }^{1, ~ *}$, John Eze ${ }^{1}$, Bolaji Akanni ${ }^{2}$, Ikponmwosa Gold ${ }^{2}$ \\ ${ }^{1}$ Department of Surgery/National Cardiothoracic Center of Excellence (NCTCE), University of Nigeria Teaching Hospital (UNTH), \\ Ituku-Ozalla, Enugu, Nigeria \\ ${ }^{2}$ Department of Surgery, University of Nigeria Teaching Hospital, Ituku-Ozalla, Enugu, Nigeria
}

Email address:

Igbochinanya2@yahoo.com (I. Nwafor),ikechukwu.nwafor@unn.edu.ng (I. Nwafor)

${ }^{*}$ Corresponding author

\section{To cite this article:}

Ikechukwu Nwafor, John Eze, Bolaji Akanni, Ikponmwosa Gold. The Scope of Clinical Thoracic Surgery Practice in Nigeria: 13-Year Single Center Review. International Journal of Cardiovascular and Thoracic Surgery. Vol. 6, No. 6, 2020, pp. 79-84.

doi: $10.11648 /$ j.ijcts.20200606.14

Received: November 9, 2020; Accepted: November 19, 2020; Published: December 22, 2020

\begin{abstract}
Background: Thoracic surgery as one of the oldest surgical specialties to have branched off from general surgeryhas a relatively wide scope, covering the diagnosis and treatment of the diseases affecting the various regions ofthechest. The practice of this specialty and challenges affecting it in Nigeria is hereby reviewed. Aims/Objective: To review the scope of clinical thoracic surgery practice in Nigeria including its challenges and compare same with international standard. Methods: For a period of 13 years (2007-2019), the practice of clinical thoracic surgery in Nigeria was reviewed with data from the National Cardiothoracic Center of Excellence (NCTCE). The social-demography profile of the involved patients, the congenital and acquired pathologies of the various anatomic regions of the chest, diagnosis and treatmentmethodologies including outcomes and challenges were extracted from the database, reviewed and analyzed. Results: A total of 1883 general thoracic pathologies in 1200 patients were managed. Of this number, pleural pathology accounted for the highest number $(\mathrm{n}=687,35.6 \%) .657$ males and 543 females were involved with aM: F ratio of 1:0.8. Of 1883 cases, $1283(68.1 \%)$ had some form of surgical interventions. Within this group, chest tube drainage \pm pleural biopsy/pleurodesiswasthehighest $(\mathrm{n}=611$, 47.6\%). Late presentations of malignant lung diseases, lack of expertise and equipment for minimal access techniques were some of the challenges. Conclusion: General thoracic surgery as a mono-specialty should be embraced, encouraged and upgraded by the training institutions in our sub-region since the workload for experts in the specialty is enormous.
\end{abstract}

Keywords: Scope, Thoracic, Nigeria, Training Institutions, Chest

\section{Introduction}

Thoracic surgery involves the surgical treatment of thoracic trauma, pulmonary and esophageal diseases. The volume of thoracic surgery has increased, subsequent to an increased incidence of trauma and cancer [1] The scope of privileges in general thoracic surgery includes the evaluation, diagnosis, treatment and consultation for patients with congenital and acquired abnormalities of the chest wall, lungs, pleura, and mediastinal structures; and traumatic injuries to the chest and cardiothoracic structures [2]. Thoracic surgeons assess, stabilize, and determine the disposition of patients with emergent conditions in accordance with medical staff policy.

The successful practice of thoracic surgery is via a team affair and members of this team usually includes surgeons, anaesthesiologists, pain management specialists, nurses, physiotherapists, respiratory therapists, occupational therapists, dietician and social workers [3]. A detailed and structured preoperative evaluation is very vital for successful intra-operative and postoperative outcome [3, 4]. The postoperative events that have significant bearing on recovery include but not limited to removal of all or part of lungs, painful incisions, retention of secretions, change in the shape and mechanics of thoracic cage, reconfiguration of gastrointestinal continuity which may result in suboptimal 
pulmonary function, reduced appetite, frailtyand increased risk of aspiration [5].

Shortly after the introduction of laparoscopic videoassisted techniques there was a real revival of thoracoscopic procedures and the term VATS, video-assisted thoracic surgery, was introduced. VATS is presently used for a variety of thoracic diseases including lung cancer [6]. For patients with lung cancer, preoperative evaluation of the mediastinal lymph nodes is important to estimate local operability and/or to consider the necessity of neoadjuvant treatment. Cervical mediastinoscopy $(\mathrm{CM})$ is generally accepted as a safe and highly accurate procedure in the staging of lung cancer [7]. Surgical use of robotics, or computer-assisted surgical systems (CAS), has evolved over the last 10 years, for the treatment of chest diseases, however, the development has really occurred in the last 3 to 4 years [8].

General thoracic procedures can be divided into minor, major and large/specialistic, according to their complexity and costs, the latter requiring specific training and dedication due to their complexity and low numbers: knowledge of all aspects of pathophysiology, epidemiology, diagnosis, treatment and postoperative care of patients with surgical disease of the chest [9]. Surgeons working in a general thoracic (GTS) unit or department must be competent in all domains of a general thoracic surgical practice: preoperative, intra-operative and postoperative. They must be able to participate in multidisciplinary team discussions on treatment of diseases of the chest.

\section{Materials and Methods}

For a period of 13 years (2013-2019), the practice of clinical thoracic surgery in Nigeria was reviewed with data from the National Cardiothoracic Center of Excellence (NCTCE). The socio-demographic profiles of the involved patients, the congenital and acquired pathologies of the various anatomic regions of the chest, diagnosis and treatment methodologies including outcomes and challenges were extracted from the database, reviewed and analyzed.

Data were analyzed using IBM Corp released 2011, IBM SPSS Stastitics for windows, version 20.0, Armonk, NY; IBM Corp. IBM Corp. Rates and proportions were calculated with 95\% confidence interval. The proportions were compared using student's $t$-tests. Level of significance was set at $\mathrm{P}<0.5$.

In our tertiary hospital, the National Cardiothoracic Center of Excellence has dedicated theater, but not wards or ICU for thoracic surgical patients. They are 6 surgeons, 3 anaesthetistis which later reduced to 2,8 theater nurses, 3 biomedical engineers and 3 theater technicians. The practice is affected by interdependence with services of other specialties in the hospital like Respiratory medicine, Radiology, Histopathology, Radio-oncology, Pharmacy, Microbiology Haematology and Chemical pathology as well as Financial Accounts Department.

\section{Results}

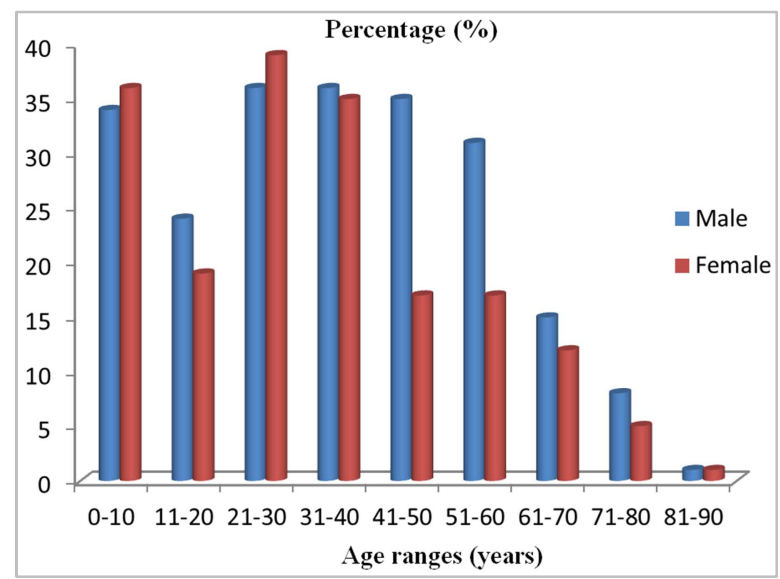

Figure 1. He age ranges and gender distributions of patients involved in clinical thoracic surgical.

This figure shows the distributions of age ranges in years for both males and females. In this group the age ranges of 21-30 years were the highest for both genders. This was followed by age ranges of 31-40 years. The least affected was the age range of $81-90$ years.

Table 1. Surgical Pleura Pathology.

\begin{tabular}{lll}
\hline Types of pathology & Number & Percentage (5) \\
\hline Chronic empyema & 60 & 8.7 \\
thoracis \pm Bronchopleural Fistula & & \\
Malignant pleura effusion & 211 & 30.7 \\
Traumatic haemothorax & 25 & 3.6 \\
Thoracic endometriosis syndrome (TES) & 10 & 1.5 \\
Pneumothoraxes & 25 & 3.6 \\
Chylothorax & 2 & 0.3 \\
Benign Pleural effusions & 350 & 50.9 \\
Pleural based masses & 4 & 0.6 \\
& 687 & 100 \\
\hline
\end{tabular}

This table showed the distributions of various pleura and pleural space pathologies. Benign or nonmalignant pleural effusions were the highest, followed by malignant pleural effusions (MPE) and chronic empyema thoracis with or without bronchopleural fistula (BPF) respectively. Pleural based masses warranting tru-cut or open biopsies were the least.

Table 2. Surgical Chest wall pathology.

\begin{tabular}{llll}
\hline S/No & Chest wall pathology & Number & $\begin{array}{l}\text { Percentage } \\
(\%)\end{array}$ \\
\hline 1 & Anterior chest wall masses, breast & 90 & 32.4 \\
2 & cancer excluded & 15 & 5.4 \\
3 & Osteomyelitis of ribs & 5 & 1.8 \\
4 & PyogenicChest granuloma & 50 & 19.0 \\
5 & Blunt chest injury with intact pleura & 10 & 3.6 \\
6 & Posterior chest wall masses & 1 & 0.4 \\
& Intrathoracic chest wall mass & 15 & 5.4 \\
7 & Flail chest & 6 & 2.2 \\
8 & Sternal tumours & 2 & 0.7 \\
9 & Clavicular tumours & 75 & 27.0 \\
10 & Sternal fractures & 8 & 2.9 \\
11 & Chronic sternal wound sinus & 1 & 0.4 \\
Total & & 278 & 100 \\
\hline
\end{tabular}


This table showed the distributions of chest wall pathologies. Anterior chest wall masses were dominant followed by traumatic rib fractures and blunt chest injuries with intact pleura. Intrathoracic chest wall mass and chronic

sternal wound sinuses were the least.

Table 3. Surgical pathology (tracheobroncheal tree/lungs).

\begin{tabular}{llll}
\hline S/No & Ttracheobronchial tree/lung pathology & Number & Percentage (\%) \\
\hline 1 & Massive haemoptysis & 10 & 1.8 \\
2 & Foreign body in the airway & 30 & 5.3 \\
3 & Primary lung cancer & 150 & 26.4 \\
4 & Secondary lung cancer & 200 & 35.2 \\
5 & Destroyed lung syndrome (PTB) & 50 & 8.8 \\
6 & Lung abscess & 13 & 2.3 \\
7 & Benign lung masses & 70 & 12.3 \\
8 & Bronchogenic cyst & 2 & 0.4 \\
9 & Lung contusions & 15 & 2.6 \\
10 & Traumatic lung lacerations & 25 & 4.4 \\
11 & Lung infarction & 2 & 0.2 \\
12 & Interstitial lung diseases & 1 & 0.2 \\
13 & Short segment cervical tracheal stenosis & 1 & 100 \\
Total & & 569 & \\
\hline
\end{tabular}

In this table the pathologies of the tracheobronchial tree/lungs were displayed. Secondary lung cancer was the highest followed by primary lung cancer. The least were interstitial lung diseases and short segment tracheal stenosis.

Table 4. Surgical mediastinal pathology.

\begin{tabular}{llll}
\hline S/No & Mediastinal pathology & Number & Percentage (\%) \\
\hline 1 & Anterior mediastinal masses & 10 & 22.2 \\
3 & Posterior mediastinal masses & 4 & 9.0 \\
4 & Mediastinal masses with superior vena cava syndrome & 3 & 6.7 \\
5 & Retrosternal goiter & 5 & 11.1 \\
6 & Myaestina Gravis & 8 & 17.8 \\
7 & Thymomas & 15 & 33.3 \\
Total & & 45 & 100 \\
\hline
\end{tabular}

This table showed the distributions of the pathologies of the mediastinum. Thymomas were the highest followed by other anterior mediastinal masses. The least was the mediastinal masses with superior vena cava syndrome (SVS).

Table 5. Surgical pericardium pathology.

\begin{tabular}{llll}
\hline S/No & Pericardial pathology & Number & Percentage (\%) \\
& Pericardial effusion & 65 & 52.9 \\
& Massive pericardial effusion with impendingtamponade & 20 & 16.3 \\
& Effusive constrictive pericarditis & 10 & 8.1 \\
& Cardiac tamponade & 8 & 6.5 \\
& Constrictive pericarditis & 14 & 11.4 \\
& Pyopericardium & 1 & 0.8 \\
& Haemopericardium & 5 & 4.1 \\
Total & & 123 & 100 \\
\hline
\end{tabular}

\section{Percentage(\%)}
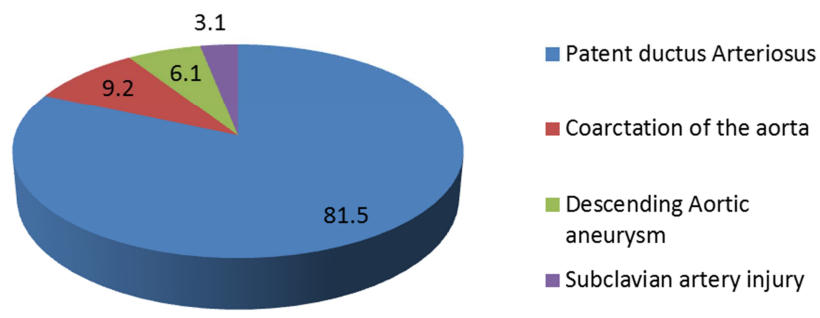

Figure 2. Thoracic vascular pathology.
Percentage(\%)

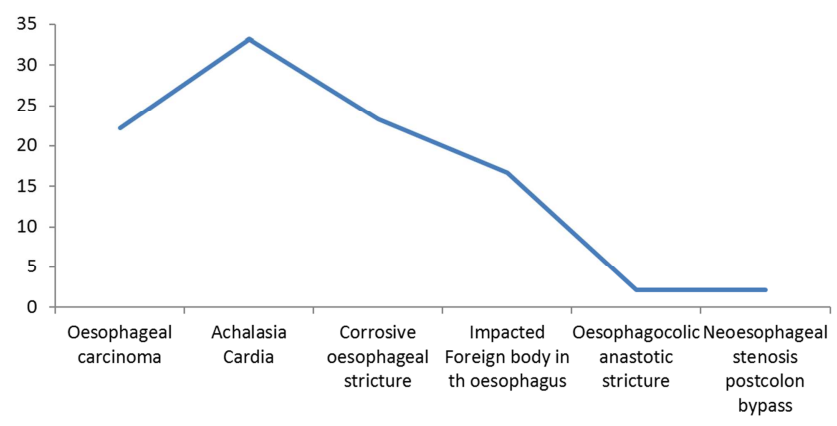

Figure 3. Surgical pathology of the oesophagus. 
The table showed the distributions of the pathologies of the pericardium. Large pericardial effusion warranting closed or open drainage was the highest, followed by massive pericardial effusion with impending cardiac tamponade. One case of pyopericardium was the least.

This figure showed the thoracic vascular pathologies managed during the envisaged period. Patent ductus arteriosus (PDA) was the highest followed by cor-actation of the aorta, The least was subclavian artery injury.

This figure showed the distributions of the surgical pathologies of the oesophagus. Achalasia cardia was the highest followed by corrosive oesophageal stricture. Oesophagocolonic anastomotic stricture and neooesophageal stenosis were the least

This figure showed the distributions of the surgical pathologies of the diaphragm. Traumatic diaphragmatic rupture
(TDR) was dominant followed by hiatal hernias. The least was TDR with herniation through the central tendon of diaphragm.

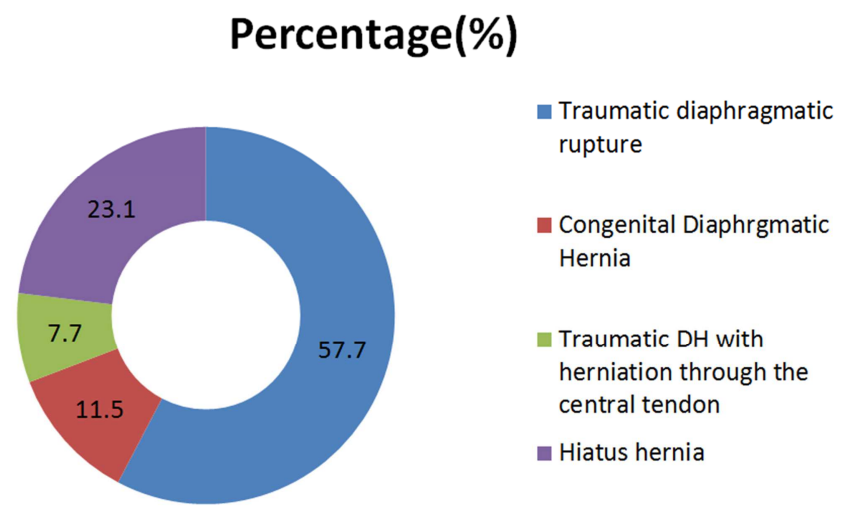

Figure 4. Surgical Pathology of the diaphragm.

Table 6. The number of thoracic surgical procedures

\begin{tabular}{|c|c|c|c|}
\hline S/No & Thoracic surgical procedures & Number & Percentage (\%) \\
\hline 1 & Chest wall resection \pm reconstruction & 106 & 8.6 \\
\hline 2 & Chest tube drainage (CTTD)/pleural biopsy with Abraham's needle & 611 & 47.6 \\
\hline 3 & Pleurectomy\& lung decortications & 70 & 5.5 \\
\hline 4 & Subxiphoid pericardial window & 90 & 7 \\
\hline 5 & Pericardiectomy & 24 & 1.9 \\
\hline 6 & Monald"s procedure/percutaneous drainage of lung abscess & 3 & 0.2 \\
\hline 7 & Lobectomy (upper/lower) & 30 & 2.3 \\
\hline 8 & Pnuemonectomy & 70 & 5.5 \\
\hline 9 & Completion pneumonectomy & 5 & 0.4 \\
\hline 10 & Clagget procedure & 6 & 0.5 \\
\hline 11 & Oesophagectomy + cervical oesophagostomy + gastrostomy & 10 & 0.8 \\
\hline 12 & Oesophagocardiomyotomy (Modified Heller's procedure) & 30 & 2.3 \\
\hline 13 & Coarctation of aorta repair & 6 & 0.5 \\
\hline 14 & Colon bypass & 21 & 1.6 \\
\hline 16 & Annerysmorraphy (DTA) & 5 & 0.5 \\
\hline 17 & Vascular repair (subclavian artery) & 2 & 0.2 \\
\hline 18 & Ligation of Patent ductus Arteriosus & 53 & 4.1 \\
\hline Total & & 1,283 & 100 \\
\hline
\end{tabular}

\section{Percentages (\%)}

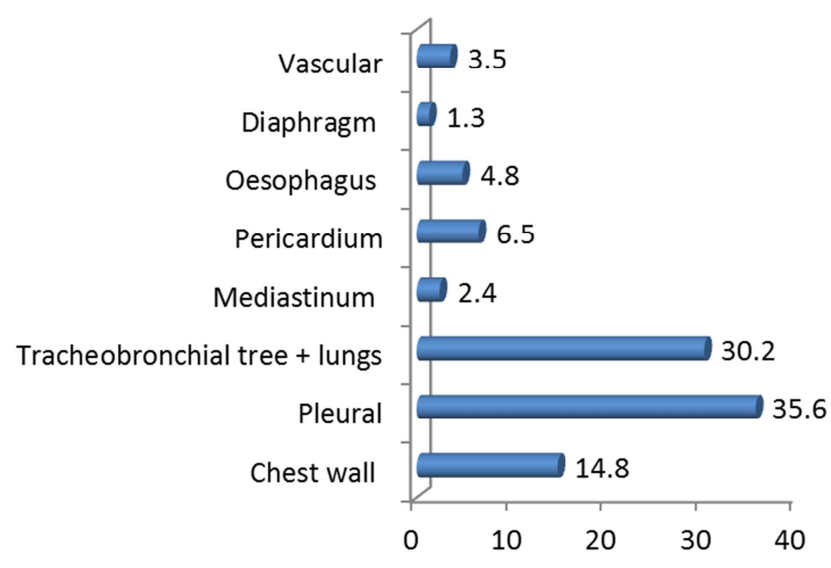

Figure 5. Thoracic anatomic regionalpathologies.

This table showed the distributions of the number of thoracic surgical procedures performed within the envisaged period. Chest tube drainage (CTTD)/pleural biopsies with Abraham's needle was the highest followed by Trucut biopsy\&minithoracotomy for lung masses. The least was Monald"s procedure/percutaneous drainage of lung abscess.

This figure showed the distributions of thoracic anatomic regional pathologies managed. Pleural region was significant followed by the trachobronchial tree/lungs. The least was the diaphragmatic region.

\section{Discussion}

Thoracic Surgery is that branch of surgery concerned with congenital and acquired diseases of the chest wall, mediastinum, lungs, trachea, pleura, esophagus, stomach and diaphragm. At a tertiary hospital in Nigeria, a center was designated National Cardiothoracic Center of Excellence (NCTCE) in cardiac, thoracic and vascular Surgery as far back as in 1984 [10]. The surgeons are mixed surgeons for the 3 specialties, however the practice of cardiac 
surgeryespeciallyOpen Heart Surgery is very limited due to deficiency in requisite equipment, inadequate skills among the members of the multidisciplinary cardiac tea $=-$ and funding [11].

The field of cardiothoracic and vascular surgery encompasses three major disciplines-cardiac, general thoracic and vascular surgery. In the early stages of evolution, these three fields were practiced by the same individuals. This is the case even now in several practice settings all over the world. However, maturity in the development of each discipline led to sub-specialization and specific training programs, clinical product lines and academic departments, not necessarily in that order. The last 50 years have seen that happen, particularly to general thoracic surgery, in North America and Europe. This sub-specialization has led to focused research and clinical innovation which in turn has led to significant improvement in patient outcomes [12].

At our center, the thoracic surgery is practiced fully and the organization of the practice is thus: $24 / 7$ emergency cover is provided by general thoracic surgical consultants with residents who are able to deal with the full range of thoracic surgical emergencies including 24/7 cover of thoracic surgical inpatients in surgical, pediatric, medical, oncology and gynaecological wards. There are 3-day weekly thoracic surgery out-patient clinics provided by consultants, assisted by residents. There are 3-day weekly thoracic surgery operations for elective cases, provided by consultants assisted by residents.

With this organization, our center was able to provide the procedures for the pathologies identified in tables 2-6 and figures 2-4. In the area of chest wall pathology, 278 (14.8\%) cases were managed. In theprevious work ofNwafor et al al [13] in the same center, 158 chest wall tumours in 158 patients over a 15 -year period were described. In the pleura and lungs/tracheobronchial tree, 687 (36.5\%) and 569 (30.2\%) cases respectively were managed. Similarly, in the mediastinum and pericardium including oesophagus, 45 $(2.4 \%), 123(6.5 \%)$ and $100(5.3 \%)$ cases were managed respectively. The thoracic vascular $(n=65,3.5 \%)$ as well as diaphragmatic $(n=100,5.3 \%)$ cases respectively were treated.

In a related study by Qiogzhen Li et al [14] at Shanghai Jiabong University Chest hospital, 62, 571 thoracic surgery procedures requiring general anaesthesia were done for a period of 11 years. Here lung surgery $(n=49732$,$) ,$ oesophageal surgery $(n=4975)]$, mediastinal surgery $(n=699)$, tracheal surgery $(n=581)$ and others $(n=292)$ were the components of the procedures. Also, in another study, Ren Jing et al [14], carried out a study involving thoracic surgery for non small lung cancer (NSLC) for 5 years in 453 patients [15]. In Japan, in 1986, the number of general thoracic surgery cases were 15,544 , which increased to 75,306 in 2013. Furthermore, the number of lungcancer operations performed in 2013 was 37,008 , occupying $49.1 \%$ of all general thoracic operations [16]. The number of lung operations increased from 6,421 in 1986 to 37,008 in 2013, a 5.76-fold increase during those 28 years. According to the Japanese Association of Thoracic Society (JATS) database, the entire number of mediastinal tumors surgically treated throughout Japan in 2013 was 4,780 [16].

\section{Challenges}

As a low-in-come-country, the practice of minimal access technique in thoracic surgery is virtually absent due to nonexistence of requisite skills and equipment. As a result, patients desirous of such procedures are lost to medical tourisms [17]. To remain competitive, the general thoracic surgeon will have to keep pace with technologic advances and maintain a current knowledge in the field of thoracic oncology [18]. In the practice of general thoracic surgeries (GTS) in our center, there are limitations imposed by interdependence on other disciplines especially the anesthetists. The ratio of 6 surgeons to 2 anaesthetists is grossly inadequate and this has significant bearings in the number of cases managed surgically. In the 13-year review, there was a 7-year period of surge in foreign cardiac surgery missions in our center [11]. General thoracic cases except emergencies were usually kept in abeyance during the period of the missionsbecause, the dedicated theater and the staff were usually occupied. This affected the number of GTS cases managed.

In addition, brain drain syndrome due to poor remuneration of workers, poor public power and water supply and very few altruistic blood donors in poorly equipped national blood banks $[19,20]$ are some of the numerous challenges affecting the GTS practice in our center, which happens to be one of the main accredited training centers for cardiothoracic surgeryby West African College of Surgery (WACS) in West African Sub-region.

\section{Conclusion}

The scope of GTS practice even as a mono-specialty in Nigeria with a population of over 200 million is wide and can become wider if governments, non-governmental organizations and public spirited individuals including the regulator of the training institutions (West African College of Surgeons) and National Postgraduate Medical College of Nigeria (NPMC) can put hands on the deck and ensure that appropriate things are done.

\section{Declarations}

Acknowledgment: The authors appreciates the contributions of other Cardiothoracic Surgeons like Prof $\mathrm{CH}$ Anyanwu, Prof MAC Aghaji, Prof N Ezemba and Dr AV Okwulehie including the anaesthetists, Associate Prof FOnyekwulu and Dr Okorie as well as the entire theater and ICU nurses in the production of this manuscript.

\section{Conflict of Interest}

The authors do not have any conflict of interest. 


\section{Funding}

There was no external funding for the production of this manuscript.

\section{Ethical Clearance}

This manuscript is the product of the audit of work in our center and is exempted from ethical clearance.

\section{References}

[1] Alesssandro B, Pierine EF. European Guidelines on study and qualification of General Thoracic Surgery, European Journal of Cardiothoracic Surgery 2014; 45: 779-786.

[2] Heikki T. General Thoracic Surgery as a monospecialty - a realistic vision? European Journal of Cardiothoracic Surgery 2002; 21 (1): 1-4.

[3] Eagle KA, Berger PB, Calkins H. ACC/AHA-guidelines of update for perioperative cardiovascular surgery. Executive summary. Circulation 2012; 105: 1257-67.

[4] Boysen PG, Perioperative Management of the thoracotomy patient. Clin Chest Med 1993; 14: 321-33.

[5] Lyer A, Yadav S. Postoperative Care and Complications after Thoracic Surgery. Principles and Practice of Cardiothoracic Surgery, Chapter 3: published June $12^{\text {th }} 2013$ by IntechOpen Access.

[6] Schil V, Paul E. 12 ${ }^{\text {th }}$ World Conference on Lung cancer: Advances in Surgical Staging using Thoracoscopy or Video Assisted Thoracoscopy. Journal of Thoracic Oncologyn2007; 2 (8): Suppl 4.

[7] Falase B, Sanusi M, Animasahun A, Mgbeijah O, Majokodunmi A, Nzewi OC, et al. The challenges of cardiothoracic surgery practice in Nigeria: 12-year institutional experience. CardiovascDiagTher 2016: 6 (suppl 1): S27-S43.

[8] Kernstine KH, Robotics in Thoracic Surgery. The American Journal of Surgery 2004; 188 (4): 89-97.

[9] Darling GE, Maziak DE, Clifton JC. The Practice of Thoracic Surgery in Canada. Can J Surgery 2004; 47 (6): 438-445.
[10] Nwafor IA, Eze JC, Anyanwu CH, Ezemba N, Onyia UOC, Ewerem NJ. The Scope of cardiac Surgery at National Cardiothoracic Center of Excellence in Nigeria: 3-Year Review. J Vasc Med Surg 2017; 5 (308): 2.

[11] Nwafor IA, Eze JC, Status of Congenital Heart Defects in Nigeria. The Role of Cardiac Surgery, World J Cardiovascular Surgery 2019: 9 (7): 63-72.

[12] Yendamuri S. Thoracic Surgery in India: Challenges and Opportunities. J Thorac Dis 2016; 8 (sppl 8): S596-S600.

[13] Nwafor IA, Okafor OC, Eze JC, Ezemba N. Histology of Chest wall tumours: 15 years Single Center Experience. NigJ of Medicine 2017; 26 (3): 284-289.

[14] Qiongzhen Li, Xiaofeng Z, Meiying X, Jingxiang W. A retrospective analysis of 62,571 cases of perioperative adverse events in thoracic surgery at teaching hospital in a developing country. J of Cardiothoracic surgery 2019; 1498: 1-7.

[15] Jing R, He S, Dai H, Lin F, Ge W, Tao G, et al. Incidence and risk factors of postoperative pulmonary complications after thoracic surgery for early non-small cell lung cancer.

[16] Okumura M, Trends and current status of general thoracic surgery in Japan revealed by a review of nationwide databases. Journal of Thoracic Disease 2016; 8 (8): 2077-6624.

[17] Omisore, E. O., Agbabiaka, H. I. Factors Influencing Patronage Of Medical Tourism In Metropolitan Lagos, Nigeria International Journal of Scientific \& technology Research 2016; 5 (14): 32-41.

[18] Faber LP, General thoracic surgery in the year 2010. Annals of Thoracic Surgery 1993; 55 (5): 1326-31.

[19] Nwafor IA, Eze JC, Nwafor MN. Establishing a sustainable Open Heart Surgery Program in Nigeria, a low-income country: Which is the best model? Cardiology in the Young 2009; 29 (12): 14-1493.

[20] Nwafor IA, Eze JC, Ezemba N, Chinawa JM, Onyekwulu Fa, Nwafor MN, Changes in Open Heart Surgery Protocol and Outcome in a Nigeria National Cardiothoracic Center of Excellence over 42 years. Therapeutic Advances in Cardiology 2017; 1 (2): 97-104. 